\title{
La responsabilidad social empresarial en el área medioambiental: una obligación constitucional en Colombia
}

\section{Corporate Social Responsibility in the environmental area: a constitutional obligation in Colombia}

https://doi.org/10.15332/iust.v0i16.2402

\author{
Paula Nathalia Correal Torres \\ Abogada, especialista en Derecho Procesal, Universidad Santo Tomás, Bucaramanga, Colombia; Maestría en Justicia \\ Constitucional (c), Universidad de Guanajuato, México. \\ Correo electrónico: paula.correal.torres@gmail.com
}

\begin{abstract}
Resumen
Las prácticas socialmente responsables se establecen como obligación constitucional para dar cumplimiento a los principios de función social y ecológica de la empresa, y se traducen en preservación de recursos naturales, en protección a la biodiversidad y en garantía de derechos humanos como la salud y el medioambiente sano. Estos derechos consagrados no solo en la Carta Magna, sino en instrumentos internacionales se constituyen como compromisos del Estado, cuyo incumplimiento puede derivar en responsabilidad de él mismo ante escenarios internacionales. La afirmación sobre la obligatoriedad en el cumplimiento de la Responsabilidad Social Empresarial en el área medioambiental se sustenta en el constitucionalismo principialista, que defiende la obligatoriedad de la totalidad del texto constitucional y exige un camino para garantizar los derechos y principios allí reconocidos. Este artículo construye un criterio de interpretación respecto de la obligatoriedad de la figura de la Responsabilidad Social Empresarial en el área medioambiental, a partir del análisis de normativa nacional, esencialmente de la Constitución Política de Colombia, y de normativa internacional, estudiando aquellos instrumentos que regulan la protección del medioambiente.
\end{abstract}

Palabras clave: Prácticas socialmente responsables, protección medioambiental, función social y ecológica de la propiedad, Estado social de derecho.

\begin{abstract}
Socially responsible practices are established as a constitutional obligation to comply with the principles of social and ecological function of the company, and they are translated into preservation of natural resources, protection of biodiversity and guarantee of human rights such as health and the environment. These rights enshrined not only in the constitution, but also in the international instruments are constituted as State commitments, whose breach may result in the State's responsibility before international scenarios. The assertion about the obligation to comply with Corporate Social Responsibility in the environmental area is based on principialist constitutionalism, which defends the obligatory nature of the entire constitutional text and requires a way to guarantee the rights and principles recognized therein. This article constructs a criterion of interpretation regarding the obligatory nature of the figure of the Corporate Social Responsibility
\end{abstract}


in the environmental area, from the analysis of national regulations, essentially of the Political Constitution of Colombia, and of international regulations, studying those instruments that regulate the protection of the environment.

Keywords: Socially responsible practices, environmental protection, social and ecological function of the property, social rule of law.

\section{Résumé}

Les pratiques socialement responsables constituent une obligation constitutionnelle de respecter les principes de fonction sociale et écologique de l'entreprise et se traduisent par la préservation des ressources naturelles, la protection de la biodiversité et la garantie des droits de l'homme tels que la santé et l'environnement. en bonne santé Ces droits consacrés non seulement dans la magna Carta, mais également dans les instruments internationaux, constituent des engagements de l'État, dont la violation peut découler de sa responsabilité dans des scénarios internationaux. L'affirmation concernant le caractère obligatoire de la responsabilité sociale des entreprises dans le domaine de l'environnement repose sur le constitutionnalisme traditionnel, qui défend le caractère obligatoire de l'ensemble du texte constitutionnel et exige une voie pour garantir les droits et les principes qui y sont reconnus. Cet article établit un critère d'interprétation concernant le caractère obligatoire de la figure de la responsabilité sociale de l'entreprise dans le domaine de l'environnement, sur la base de l'analyse des réglementations nationales, essentiellement de la Constitution politique de la Colombie, et des réglementations internationales, qui étudient les instruments qui régissent La protection de l'environnement.

Mots-clés: Pratiques socialement responsables, protection de l'environnement, fonction sociale et écologique de la propriété, état de droit social. 


\section{La responsabilidad social empresarial en el área medioambiental: una obligación constitucional en Colombia}

Paula Nathalia Correal Torres

\section{INTRODUCCIÓN}

La Responsabilidad Social Empresarial (en adelante RSE) es una figura que busca generar los parámetros bajo los cuales las empresas deben conducir sus actividades de explotación económica, atendiendo a determinadas áreas de principal interés, como es el caso del área medioambiental. Este tipo de responsabilidad empresarial supone un reto no solo económico, sino ético y un compromiso con la sociedad en la cual despliegan su actividad económica, no obstante, algunas empresas consideran que la ausencia de una norma que incorpore la obligación taxativamente de cumplir con determinados códigos de conducta hace de esta figura un ideal filantrópico y no un deber legal o constitucional. Contrario a esta postura se logra configurar una obligación de tipo constitucional en la medida en que el ordenamiento jurídico colombiano incorpora la función social y ambiental de la empresa como núcleo de desarrollo de la sociedad y a partir de la corriente del constitucionalismo se evidencia la obligatoriedad en el cumplimiento de los lineamientos del comportamiento empresarial.

En cuanto al medioambiente, se logra establecer no solo una preocupación internacional respecto de su protección y conservación que se traduce en múltiples tratados y protocolos, sino una necesidad de cada Estado de generar las herramientas jurídicas necesarias para garantizar, que todas las personas físicas y jurídicas propendan por su conservación y defensa. En el caso colombiano dado el alto nivel de biodiversidad con que cuenta el territorio nacional, se agudiza la importancia de efectivizar los derechos al medioambiente sano, los instrumentos de derecho internacional ratificados por el Estado que propenden por la protección ambiental y todas aquellas herramientas constitucionales y legales que imprimen a los diferentes actores del conglomerado social obligaciones de protección y conservación de los recursos naturales. La preocupación internacional y nacional por el medioambiente radica en la problemática que se presenta en la actualidad por el deterioro ambiental, el desequilibrio de los ecosistemas y la explotación inescrupulosa de los recursos naturales, que exige una respuesta real, eficaz y coercitiva por parte del derecho.

Enlazando estos dos elementos se logra advertir la imperiosa necesidad de que las empresas como principales explotadores de los recursos del territorio en el cual desarrollan sus actividades económicas y como núcleos de desarrollo social, 
tengan a su cargo responsabilidad social enfocada al área medioambiental, sin la necesidad de exigir una norma que les indique la obligación de seguir los parámetros de comportamiento social empresarial, bajo el entendido de que al hacerlo estarían cumpliendo con los principios constitucionales que les imponen la función social y ambiental.

\section{RESPONSABILIDAD SOCIAL EMPRESARIAL AVANCES Y DESAFÍOS}

La empresa cuenta con un papel central en el desarrollo de la sociedad, su carácter impulsor de la economía la posiciona en un lugar predominante, es decir, la explotación de su actividad económica cuenta con grandes facilidades y libertades, sin embargo, esta libertad de creación, organización y funcionamiento llega a impactar en el entorno en el que se desarrolla. Toda empresa cuenta con grupos de interés que la rodean, se denominan stakeholders ${ }^{l}$ y se refiere a aquellos grupos o individuos que puedan verse afectados por el actuar empresarial, algunos de estos pueden ser empleados, proveedores, ambientalistas, gobierno, clientes y consumidores en general.

De acuerdo con esta afectación a ciertos grupos por parte de la empresa, surge una preocupación a nivel mundial, frente al papel de las empresas en la sociedad, especialmente a finales del siglo XIX, abandonando la idea del rol de empresa limitado a conseguir ganancias, producir bienes y servicios e impulsar el aspecto económico de un determinado país, para ampliar el papel de la empresa incluyendo preocupaciones por el bienestar social. Este nuevo paradigma en la empresa y su rol se convierte en responsabilidad social empresarial, la cual inicia su aparición en 1953, dividiéndose en varias etapas, desde reconocimiento hasta compromisos mutuos. En el documento Responsabilidad Social Empresarial (RSE): evolución, presente y tendencias (Nowajewski, et al., pp. 3-5), se plantean las siguientes etapas con sus respectivas características:

1. Reconocimiento: Se ubica en el lapso de 1953 a 1970. Se caracteriza por la voluntariedad en su cumplimiento y el concepto de productividad bajo criterios éticos.

2. Despertar: Se presenta entre los años 70 y principios de los 80 y se caracteriza por la preocupación del empresario por el entorno en el cual desarrolla su objeto económico, por tanto, genera obligaciones de cara a la sociedad, sea de tipo ético, económico y discrecional.

3. Compromiso: De 1991 a 2003, los empresarios abren su actividad

1 Este término fue introducido al mundo de estrategia empresarial y responsabilidad corporativa por Edward Freeman, en 1984. En su texto Strategic management (Gestión estratégica) también explica que el origen del concepto se remonta a Adam Smith en 1759, Berle and Means en 1932 y Banard 1938, llegando a las estrategias de manejo empresarial (Freeman, 2010, pp. 31-32). 
internacional, lo que ocasiona una necesidad de delimitar el marco legal, ético y desarrollar actividades que produjeran efectos positivos frente a la sociedad y el medioambiente.

4. Compromiso empresarial y social: entre los años 2006 y 2015 se incluyen en la explotación económica aspectos de derechos económicos, sociales y medioambientales, exponiendo resultados claros de las acciones implementadas hacia cada grupo de interés.

Ahora bien, frente al concepto de la RSE, en el documento presentado por el Instituto Argentino de RSE (IARSE, s.f.), se citan conceptualizaciones de fundaciones, centros empresariales, institutos e instrumentos internacionales, a fin de evidenciar que no existe una sola definición de la figura, no obstante, sí se presentan elementos comunes en estas definiciones. Así las cosas, se podría plantear como definición que se unan estos elementos comunes: la RSE es un conjunto integral de prácticas, formas de tomar decisiones, gestión de objetivos, integración de valores y relación de la empresa con su entorno, social, económico y medioambiental, con miras a mejorar la calidad de vida y el bienestar general. Es aquella que le imprime a la empresa la obligación de observar los efectos negativos y positivos a nivel social de su actuar, encaminando la explotación económica hacia el desarrollo humano sostenible, sin dejar de lado las metas empresariales.

Las definiciones encontradas se limitan al referirse al carácter obligatorio de las prácticas socialmente responsables, lo plantean desde la ética empresarial y la conciencia corporativa, dejando de lado el aspecto jurídico que rodea a esta figura en ordenamientos jurídicos como el colombiano. Para efectos de la caracterización de la RSE y sus avances a través del tiempo, resulta enriquecedora la información planteada. Como elementos de la figura, el autor Manuel Reyno Momberg (2006, pp. 34 -35) plantea: Transparencia (información sobre la veracidad de la conducta empresarial); Materialidad (interés de la empresa en el conocimiento de las necesidades de la comunidad donde se desarrolla); Verificabilidad (la posibilidad de que entes externos revisen las actuaciones socialmente responsables); Visión amplia (sinónimo de sostenibilidad, es decir, la empresa debe tener en cuenta el impacto que produce no solo a nivel local sino a nivel global); Mejora continua (persigue la constancia en la gestión de la RSE) y, Naturaleza social (el carácter social que tiene la empresa, superior al interés económico).

Una vez se conocen algunos de sus elementos, es necesario plantear lo referente a las visiones de la figura, dado que a través de su avance en el mundo, se ha visto desde muchos ángulos y bajo diversas ópticas, debido a esto, estas visiones deben conocerse y analizarse, con la finalidad de construir con algunas de estas, una perspectiva que se adapte al modelo de ordenamiento jurídico colombiano y más que nada a la normativa internacional que le imprime deberes al Estado en materia ambiental y a la empresa como unidad de desarrollo social. Para tal fin los autores Christian Cancino y Mario Morales (2008, pp. 13-14), refieren: 
1. Visión de generar ganancias como único fin, este aspecto se refiere al cumplimiento de la RSE como deber con la sociedad, siempre y cuando genere algún beneficio económico.

2. Visión de generación de ganancias en un ámbito limitado, consiste en el respeto de las leyes y de las normas que el entorno le exige.

3. Visión de bienestar social, esta visión se basa en la ética, conociendo la capacidad que tiene de causar daño y el deber moral que tiene en su reparación.

4. Visión de empresa al servicio de la comunidad, se refiere a la empresa como ente de bienestar social.

En la Resolución AG/RES.2840 (XLIV-O/14) (Naciones Unidas, 2014), la Asamblea General de Naciones Unidas enfatiza en los compromisos que tiene la empresa frente a los derechos humanos, toda vez que parte de la siguiente premisa: que las empresas:

[...] independientemente de su tamaño, sector de actividad, contexto operacional, o estructura, desempeñan un papel importante en la vida política, económica y social, y que tienen la responsabilidad de respetar los derechos humanos en cualquier lugar en que ejerzan sus actividades, independientemente de la capacidad de los Estados de cumplir con sus obligaciones en la materia; aunque esto no disminuye el deber de los estados de proteger los derechos humanos, de conformidad con sus obligaciones de derecho internacional (Naciones Unidas, 2014, p. 1).

Este planteamiento expone la necesidad de que las empresas desplieguen su actividad económica bajo parámetros de RSE, la explotación económica discordante de la protección de los derechos humanos no es aceptable en un Estado que tiene la obligación de garantizar ciertos derechos, contenidos a nivel constitucional y en instrumentos internaciones. Esta resolución emite para los Estados compromisos como la exhortación a aquellos:

[...] Estados miembros a que den la mayor difusión posible a estos principios, facilitando el intercambio de información y compartiendo buenas prácticas de promoción y protección de los derechos humanos en el ámbito empresarial, a fin de lograr una mayor concientización sobre los beneficios de su aplicación (Naciones Unidas, 2014, p. 2).

Es así como el Estado al ser garante de los derechos humanos, es el primer llamado a exigir de las empresas un comportamiento acorde con las estrategias y principios de preservación y protección de los derechos humanos. Frente a este último aspecto, puede agregarse que a partir de edificación y exigencia de una obligación constitucional se lograría el cumplimiento de las prácticas socialmente responsables, por parte de las empresas.

Este acápite concluye con una idea general de la figura de la RSE, teniendo claro en primer lugar que se trata de acciones que debe realizar la empresa para 
coadyuvar al desarrollo sostenible del entorno en el cual desarrolla su actividad económica, en cumplimiento no solo de su ética empresarial, sino de las obligaciones constitucionales y legales que tiene de acuerdo con su rol central en la sociedad. Asimismo, queda claro que cuenta la figura con pluralidad de áreas de interés, según sus stakeholders, pero para efectos del presente artículo, se delimita el objeto del estudio al área medioambiental, que se desarrolla en el siguiente acápite.

\section{RESPONSABILIDAD SOCIAL EMPRESARIAL EN EL ÁREA MEDIOAMBIENTAL - PREOCUPACIÓN MUNDIAL}

En el acápite anterior se estableció que una de las áreas de la RSE es el medioambiente, un aspecto de total relevancia actual, puesto que el mundo está sufriendo graves deterioros en cuanto a recursos naturales, fenómenos como el calentamiento global (Earth Observatory (Observatorio de la tierra), s.f.), la excesiva polución (Environmental Protection Agencies (Agencias de Protección Ambiental), 2018), la desforestación (Davis, 2018), la contaminación de fuentes hídricas (Departamento de Asuntos Económicos y Sociales de Naciones Unidas ONU-DAES, 2014), pérdida de la biodiversidad (Naciones Unidas, s.f.), entre otras situaciones que ponen en peligro la garantía de supervivencia del ser humano, tanto en la actualidad como en generaciones futuras. De acuerdo con la gravedad del deterioro ambiental y la búsqueda constante de acciones concretas que frenen la pérdida de recursos naturales, la empresa enfrenta como reto armonizar la consecución de sus metas corporativas con políticas y acciones ambientalmente amigables.

Como muestra de dicho interés en el escenario internacional, la Organización de Naciones Unidas emite el informe Los principios rectores sobre las empresas y los derechos humanos (2011) a fin de analizar la cuestión de los derechos humanos y las empresas trasnacionales y otras empresas. Algunos de los principios resultan clarificadores de la responsabilidad de la empresa frente a los derechos humanos, como los ambientales, de esta manera, principios como la exigencia de que las empresas: a. Eviten que el desarrollo de sus actividades provoquen consecuencias negativas sobre los derechos humanos y en caso de que se presenten dichos efectos, los reparen. $b$. Prevengan las consecuencias negativas sobre los derechos humanos relacionadas con operaciones, productos o servicios prestados por sus relaciones comerciales, permite evidenciar un carácter de obligatoriedad frente a actividades preventivas y de conservación ambiental, máxime si tenemos en cuenta que la explotación económica de la empresa genera un impacto en casi todo el espectro de derechos nacional e internacionalmente reconocidos, es por tanto que su responsabilidad de respetar se aplica a todos esos derechos. En el trasegar social, ciertos derechos humanos pueden verse expuestos a un riesgo mayor que otros en algunos contextos, por la cual ameritan una atención especial. Es el caso de los derechos medioambientales, que se ven amenazados de forma permanente con la explotación de empresas en el territorio nacional, por lo cual es imperativo exigir un despliegue de acciones socialmente 
responsables, que permitan salvaguardar el derecho humano a un medioambiente sano y coadyuven a la preservación de los recursos naturales.

La especificidad del área medioambiental como parte de la RSE, se clarifica a través de instrumentos internacionales, como el libro verde, en el cual la Comisión Europea, señala que:

La RSE es una integración voluntaria por parte de las empresas, de las preocupaciones sociales y medioambientales en sus relaciones con sus interlocutores; [...] es, esencialmente, un concepto con arreglo al cual las empresas deciden voluntariamente contribuir al logro de una sociedad y de un medio ambiente más limpio [...] (Comisión de las Comunidades Europeas, 2001, pp. 3 y 7).

Es decir que la responsabilidad no solo se enmarca en un ámbito económico sino también social y medioambiental, lo cual haría que la empresa perdure más en el tiempo. En el Libro Verde se hace referencia a estas tres responsabilidades, las cuales se explican así:

- La Responsabilidad Económica sostiene que las empresas tienen como objeto para desarrollar, generar riquezas en el entorno, puesto que esto es pilar para el mismo desarrollo de esta y de igual manera tener beneficios y disminuir costes como económicos, medioambientales, sociales y de cualquier otro tipo para que sea una empresa socialmente responsable.

- La Responsabilidad Social señala que la empresa debe tener en cuenta lo que manifiesta y plantea la sociedad, mirar el comportamiento que la sociedad tiene, entonces, analizando esos aspectos la empresa debe responder a las demandas que la sociedad expresa para que de esa forma esté integrada en dicho entorno.

- La Responsabilidad Medioambiental expresa que por medio de esta responsabilidad también desarrolla la responsabilidad social que consiste en el cuidado del entorno físico, dicho cuidado es necesario para la subsistencia de la empresa, por otro lado, es fundamental llevar a cabo el desarrollo sostenible dando así respeto y cuidado al medio ambiente.

Esta caracterización de la responsabilidad ambiental, y en general de la RSE, le imprime a las prácticas un carácter voluntario (López de Medina, 2002, pp. 1-5), que dista de la realidad jurídica de la figura, pero en escenarios nacionales, como el caso colombiano, se logra identificar la obligatoriedad de las prácticas, teniendo en cuenta que es un Estado social de derecho, que le impone límites al desarrollo empresarial, basado en principios, como función social y ecológica de la propiedad y de la empresa en particular.

En el texto Gestión ambiental y responsabilidad social (Universidad Interna, 2013, pp. 17-22), se presentan una serie de instrumentos de la gestión ambiental que resultan interesantes para la aplicación de prácticas socialmente responsables, estos van desde la sensibilización del empresario, su participación e inclusión de las variables ambientales en sus proyectos, pasando por evaluaciones de impacto 
ambiental, sistemas de información ambiental y análisis de riesgos, hasta llegar a instrumentos correctivos, como multas, finanzas, tasas, auditorías ambientales, que incluyan restaurar la situación ambiental previa, reformarla y rehabilitarla. Algunos de estos instrumentos se encuentran en el ordenamiento jurídico colombiano como exigencias a la empresa en cuanto a daños y resarcimiento de estos, pero no contempla la generación de acciones permanentes y continuas que garanticen que el medioambiente en el cual se desarrolla el objeto empresarial, sea preservado, en este aspecto es que las prácticas socialmente responsables en materia ambiental se constituyen como herramienta de prevención de daños, de conservación de recursos y de garantía de los derechos humanos a un medioambiente sano, el cual se relaciona directamente con la salud y la calidad de vida de los nacionales. Es así que la exigencia de acciones concretas no solo cuando se produzca un daño ambiental (muchas veces de imposible reparación, solo admite indemnización que no se traduce en resarcimiento del daño) sino correlacionadas al actuar empresarial en la cotidianidad de la explotación económica, significa un compromiso real con el desarrollo sustentable, con la defensa de los derechos humanos y con la preservación medioambiental.

\section{PRINCIPIOS CONSTITUCIONALES EXIGIBLES A LA EMPRESA EN MATERIA AMBIENTAL, SUSTENTO LEGAL Y JURISPRUDENCIAL}

En la Constitución Política de Colombia de 1991 se plantean conceptos como la libertad de empresa ${ }^{2}$ y la iniciativa privada, como principios de la actividad empresarial. Estas libertades no tienen el carácter de ilimitadas, por el contrario, el mismo ordenamiento constitucional prevé como limites a estas los principios de función social y ecológica de la propiedad y de la empresa en particular.

2 Artículo 58. Se garantizan la propiedad privada y los demás derechos adquiridos con arreglo a las leyes civiles, los cuales no pueden ser desconocidos ni vulnerados por leyes posteriores [...] $\mathrm{La}$ propiedad es una función social que implica obligaciones. Como tal, le es inherente una función ecológica $[\ldots]$

Artículo 333. La actividad económica y la iniciativa privada son libres, dentro de los límites del bien común. [...] La empresa, como base del desarrollo, tiene una función social que implica obligaciones [...]. La ley delimitará el alcance de la libertad económica cuando así lo exijan el interés social, el ambiente y el patrimonio cultural de la Nación.

Articulo 334. La dirección general de la economía estará a cargo del Estado. Este intervendrá, por mandato de la ley, en la explotación de los recursos naturales, en el uso del suelo, en la producción, distribución, utilización y consumo de los bienes, y en los servicios públicos y privados, para racionalizar la economía con el fin de conseguir en el plano nacional y territorial, en un marco de sostenibilidad fiscal, el mejoramiento de la calidad de vida de los habitantes, la distribución equitativa de las oportunidades y los beneficios del desarrollo y la preservación de un ambiente sano. Dicho marco de sostenibilidad fiscal deberá fungir como instrumento para alcanzar de manera progresiva los objetivos del Estado Social de Derecho (Congreso de la República, 1991). 
A fin de comprender la esencia de estos principios, partiendo de su conceptualización como normas finalistas, que persiguen un estado de cosas ideal, el autor Humberto Ávila, presenta una cuestión sumamente indispensable para desarrollar el objeto de la investigación, al señalar:

[...] si ha de buscarse el estado de cosas y este solo se realiza mediante determinados comportamientos, estos pasan a constituir necesidades practicas sin cuyos efectos no se realiza la progresiva promoción del fin, [...] en otras palabras, la positivación de principios implica la obligatoriedad de que se adopten los comportamientos necesarios para su realización, salvo si el ordenamiento jurídico predetermina el medio a través de reglas de competencia [...] (2011, pp. 70-71).

En el caso colombiano, para hacer efectivos los principios de función social y ecológica de la propiedad y de la empresa en particular, se requiere la adopción de prácticas socialmente responsables, que los materialicen. Más allá de señalar los comportamientos necesarios, también se debe propender por la exigencia de estos por parte del Estado como garante de estos principios constitucionales. En palabras del autor "los principios, aunque indeterminados, no lo son de forma absoluta. Podría haber incertidumbre en cuanto al contenido del comportamiento que ha de adoptarse, pero no en cuanto a su especie: lo que es necesario para promover el fin es debido (Ávila, 2011, p. 72), esta afirmación da margen a la libertad de empresa en el despliegue de su actuar, pero la limita razonablemente para conseguir el fin debido, es decir, dar cumplimiento a los principios que protegen los derechos humanos.

Una vez aclarada la esencia de los principios constitucionales de manera sintética, es importante determinar la naturaleza de los derechos ambientales que le imprime a la empresa la obligación de generar acciones que impacten en su garantía y protección, para tal labor, el autor Juan de Jesús Góngora (2008, p. 283) expone algunos avances en materia de protección de DESCA, planteando la idea de preocupación en el escenario mundial por este tipo de derechos, la razón de la insistencia internacional de proteger derechos como los ambientales, radica en el estado de deterioro de las condiciones de vida de algunas poblaciones en determinados territorios. Como criterio personal, la idea de afectación en diferentes niveles sociales, la considero una realidad palpable, sin embargo, la afectación que se presenta por explotación del entorno en el marco de desarrollo empresarial, afecta los derechos de todos, toda vez que el deterioro ambiental no conoce de circunscripciones territoriales, ni demarcaciones temporales, ya que los recursos naturales resultan la única garantía de supervivencia del ser humano, tanto para las poblaciones actuales como para generaciones futuras. Los avances de protección que refiere el autor del órgano supranacional regional, son trascendentes en la medida en que poco a poco se han ido configurando compromisos para los Estados y los entes privados frente a derechos humanos económicos, sociales, culturales y ambientales; no obstante, aun hace falta un mayor compromiso y exigibilidad del Estado hacia las empresas, siendo estas, no solo impulsoras de los Estados, sino factores de riesgo en materia de conservación ambiental. 
A nivel internacional la exigencia de protección ambiental y conservación de recursos naturales se puede sintetizar de la siguiente manera:

- Conferencia de las Naciones Unidas sobre Medio Ambiente y Desarrollo, celebrada en Río de Janeiro en 1992, establece las políticas para la conservación del ambiente de la siguiente manera:

a) Paradigma que ubique el concepto de sustentabilidad como eje rector de la estrategia de desarrollo económico y social.

b) Integrar las políticas ambientales, económicas y sociales, asegurando que estas incorporen la sustentabilidad.

c) Sistema de indicadores público y transparente que midan los avances o retrocesos hacia la sustentabilidad.

d) Participación de la sociedad civil en el diseño y ejecución de políticas ambientales y en la evaluación de políticas sectoriales (1992).

- El Protocolo de Kioto (1998) es un acuerdo internacional vinculado a la Convención Marco de Naciones Unidas sobre el Cambio Climático: Establece objetivos vinculantes para 37 países industrializados y la Comunidad Europea para la reducción de gases de efecto invernadero. En este punto entra el papel de la empresa, porque en el desarrollo de su actividad empresarial, ella es una de las principales productoras de este tipo de daño al medio ambiente incluso en una mayor cantidad que la población civil, y por tanto debe ser responsable a su actuación teniendo en cuenta la relevancia que tiene dicha normatividad.

- Acuerdo de parís (Naciones Unidas, 2015): El cambio climático es un problema de toda la humanidad, por ello exige que se adopten medidas para hacerle frente y, asimismo, las partes deben respetar, promover y tener en cuenta sus respectivas obligaciones relativas a los derechos humanos, el derecho a la salud, los migrantes, los niños, las personas con discapacidad y las personas en situaciones vulnerables y el derecho al desarrollo.

En el texto La puerta de la justiciabilidad de los derechos económicos, sociales, culturales y ambientales en el Sistema Interamericano: relevancia de la sentencia Lagos del Campo, en el numeral 6.3 titulado "Derivación de la responsabilidad estatal", el autor plantea un avance en materia de responsabilidad estatal por hechos derivados de conductas de un tercero, incluyendo a las empresas. Al realizar un análisis sobre las jurisprudencias emitidas contra los Estados, concluye que hasta el caso Lagos del Campo, la responsabilidad se fincaba en acciones del Estado contra los derechos humanos o por omisiones de investigación y garantía de ciertos derechos como el acceso a la justicia, no obstante, con el caso Lagos de Campo, se denota un cambio, que incluye en palabras del autor, responsabilidad por haber avalado, a través de sus autoridades judiciales, una acción arbitraria de un privado (Calderón, 2018). Así las cosas, resulta un avance importante en materia de DESCA, 
especialmente respecto de derechos ambientales y la protección y garantía de estos. El reconocimiento de la empresa como factor de riesgo frente a posibles violaciones a derechos humanos y la responsabilidad estatal que puede derivar de la conducta empresarial irresponsable o atentatoria contra derechos humanos, es un punto clave frente a la exigencia de prácticas socialmente responsables hacia las empresas que realizan su explotación económica en el territorio nacional.

En materia nacional, las obligaciones ambientales son bastante extensas, especialmente en lo que se refiere a licencias ambientales y estudios de impacto ambiental, sin embargo, para efectos de este artículo se tomarán en cuenta las más relevantes, iniciando por el artículo 27 de la Ley 1382 de 2010 (Congreso de Colombia, 2010), donde se establece como deber para las empresas mineras la práctica y promoción de la RSE, incluyendo dentro de sus elementos, que allí se exponen, el logro de los objetivos sociales, el mejoramiento de la calidad de vida de la población y la prevención y reparación de los daños ambientales en la regiones o zonas donde se desarrolla la actividad minera, todo ello dentro de un marco de desarrollo humano sostenible. Considero que dicha norma al plantear la RSE como una práctica voluntaria está contradiciendo el mismo carácter de la norma, es decir, que al pertenecer al derecho, y dado el carácter coercitivo de este, en el entendido de que las disposiciones que este contenga son vinculantes para el sujeto de derecho, en este caso, la norma se refiere a los empresarios mineros, por lo tanto, estos en atención a la obligatoriedad de la leyes deben dar pleno cumplimiento a la RSE que allí se les impone y siendo el elemento ambiental de esta el objeto de la investigación, la empresa de este sector de la economía debe dar pleno cumplimiento a la protección y conservación del medio ambiente que se establece en las disposiciones allí planteadas, y así al realizar su actividad económica de una forma socialmente responsable estaría dando cumplimiento a la obligación que le impone el derecho.

Por su parte el Decreto 948 de 1995 (Ministerio del Medioambiente), expone el reglamento de protección y calidad del aire, aunque se dirige a la protección de un solo elemento del medioambiente, se evidencia la importancia que tiene este y sus elementos, para la vida humana, por ello este Decreto emite obligaciones para las personas, las empresas y el Estado, en cuanto a la conservación del aire sano, con disposiciones como la del artículo 14, de ruido ambiental, donde cobija al sector privado en la afectación que pueden producir las regulaciones sobre ruido, imponiéndole a la empresa y en sí al sector privado el deber de cuidar dicho elemento ambiental, indicándole los niveles permitidos según el sector $\mathrm{C}$, que hace referencia a las zonas con usos industriales y comerciales, oficinas, uso institucional y demás.

Como último aspecto frente a la exigibilidad de los principios de función social y ecológica de la empresa, traducidos en prácticas socialmente responsables en materia ambiental, se encuentran dos jurisprudencias relevantes para el caso y son las siguientes: 
En la Sentencia C-944 de 2008 (Corte Constitucional, 2008) se puede inferir que con la Constitución de 1991, se le otorga al medioambiente y a su protección, un carácter trascendental, donde se le considera no como un objeto de uso por parte de la comunidad, sino como un bien común, como patrimonio de la nación, por ello se hace de vital importancia su protección y conservación, además se debe tener en cuenta la crisis ambiental que desde hace varios años empezó a hacerse cada vez más notoria, y adicionalmente a esta crisis se le suma la demanda que hace la población civil al Estado para que implemente acciones de protección al medioambiente. Asimismo, esta Sentencia le otorga a la RSE en el área medioambiental el carácter de obligatoria, ya que en el artículo 334 y demás relacionados, se plantea hacia el Estado una obligación de intervención, en aras de preservar el medioambiente sano. Y como en las prácticas empresariales, se ve afectado el medioambiente, el Estado debe desplegar acciones para que las empresas se vean obligadas a innovar en el desarrollo de su actividad para no causar impactos negativos en el medioambiente y así mismo se le hace exigible la creación de acciones para su preservación.

En la Sentencia C-486 de 2009 (Corte Constitucional), se destaca el carácter preventivo de las normas medioambientales, teniendo como fin que no se generen más daños en el medioambiente y, por el contrario, mitigar los ya generados, así mismo se plantea la idea fundamental de que el Estado no es el único con la obligación protectora. Por el contrario, se busca que haya un equilibrio de intereses y que los industriales se incorporen a la protección del medioambiente, siendo estos desde el sector privado los que se benefician con los recursos ambientales.

\section{ANÁLISIS DE TESIS CONSTITUCIONALISTAS APLICABLES}

El derecho se transforma de acuerdo con el avance social y los retos que este presenta, debido a los cambios en los Estados, las corrientes y teorías del derecho han ido aumentado y ampliando sus tesis centrales. En relación con el objeto de estudio, la corriente que se aproxima y sustenta de mejor manera la supremacía de los principios analizados anteriormente, y fundamenta la obligatoriedad de la RSE en materia medioambiental para el Estado colombiano, es el Constitucionalismo principialista, sin embargo, para llegar a esta teoría, es necesario exponer los cambios que dieron lugar a esta y su caracterización a fin de comprender de forma general su contenido y sus tesis principales.

En el texto de Iusnaturalismo y Neoconstitucionalismo, del autor Luis Vigo (2015, p. 851), se plantean dos momentos del Estado, el modelo propio del siglo XIX e inicios del XX el Estado de Derecho Legal y el modelo adoptado en la segunda mitad del siglo XX, el Estado de Derecho Constitucional. Estos dos modelos o tipos de Estado cuentan con particularidades propias y difieren en varios aspectos, sintetizados a continuación: 
Tabla 1. Estado de derecho legal y constitucional

\begin{tabular}{|c|c|}
\hline Estado de derecho legal & Estado de derecho constitucional \\
\hline $\begin{array}{l}\text { Prima el derecho = ley, y por ende las disposicio- } \\
\text { nes emitidas por autoridad reconocida y vigentes } \\
\text { ante la sociedad, se imponían al conglomerado } \\
\text { social. } \\
\text { Se cree ciegamente en la omnipotencia del legis- } \\
\text { lador y se presenta la división entre iusnaturalistas } \\
\text { y positivistas }\end{array}$ & $\begin{array}{l}\text { Producto del reconocimiento a la dignidad como } \\
\text { máximo valor, y los cambios en la definición de } \\
\text { derecho (apartándose de su concepto de ley) emer- } \\
\text { ge la teoría del neoconstitucionalismo. } \\
\text { Se implementan como mandatos de optimización } \\
\text { los principios y surgen dos tipos de neoconstitu- } \\
\text { cionalistas, los positivistas y los No-positivistas. }\end{array}$ \\
\hline
\end{tabular}

Fuente: elaboración propia a partir del texto Iusnaturalismo y neoconstitucionalismo.

De acuerdo con esta división de los momentos del Estado, surgen nuevos cambios en la percepción del derecho que incluyen:

1. Que no cualquier contenido es derecho, debe existir la fórmula autoridad + vigencia social + calidad ética.

2. Un derecho con principios: este elemento resulta sumamente relevante, debido a que se pretende advertir la exigibilidad de los principios constitucionales. En este aspecto se incluyen valores, bienes o fines.

3. Argumentación: cuenta con un rol central de esta corriente al interpretar una regla o un principio.

4. Complejidad de los casos: rechaza la idea de que todos los casos sean subsumibles, algunos requieren de ponderación.

5. Judicialización: la jurisprudencia en el derecho juega un papel central, partiendo del carácter cambiante de la sociedad y por ende de las normas, los sistemas y los procedimientos para alcanzar lo que el realismo jurídico clásico denomina el triunfo de la justicia y el bien común. Este aspecto requiere un juez acucioso, que conozca los pronunciamientos y estado del derecho, quien debe verificar el umbral de justicia y el orden marco constitucional en palabras de Alexy.

6. Crisis de soberanías nacionales: este aspecto ha sufrido drásticos cambios, a partir de la era de la globalización y las empresas trasnacionales. Se ha agudizado la necesidad de rechazar poderes absolutos y reconocer la competencia (y en ocasiones última palabra) de los tribunales supranacionales, ello con base en la característica elemental de los derechos humanos de universalidad.

Con todos estos cambios paradigmáticos, un grupo de profesores de la Universidad de Génova, plantean el término Neoconstitucionalismo, como una corriente que haga frente a las nuevas concepciones del derecho, defienda la supremacía constitucional y efectivice los principios allí contenidos. La discusión desde el surgimiento de esta corriente ha aumentado cada vez más entre la comunidad académica, con autores como Ferrajoli y Manuel Atienza, en razón a la superación del formalismo 
y la tendencia hacia la interpretación, argumentación y ponderación. Como criterio personal, el término Neoconstitucionalismo resulta un tanto desafortunado y gran parte de los autores que presentan tesis respecto del constitucionalismo, sea garantista o principialista, se niegan a ser incluidos en esta categoría de neoconstitucionalistas, por tanto, pese a que en algunas obras se mantiene el término, en el presente texto se planteará el término constitucionalismo actual, y se aclarará cuando se refiera a garantista o principialista.

Actualmente se logra evidenciar la presencia del constitucionalismo en pluralidad de Estados sociales de derecho, incluido el Estado colombiano, que intentan dotar de vida jurídica a sus constituciones como norma superior de todo el ordenamiento jurídico. En este mismo sentido surge la necesidad de efectivizar los derechos de los gobernados e imponer las responsabilidades necesarias para que estos no se limiten a plasmarse en un texto normativo, sino que realmente sean protegidos y garantizados.

El constitucionalismo cuenta con pluralidad de autores que nutren su esencia con diferentes perspectivas, por lo cual es necesario conocer aquellas visiones que grandes teóricos del derecho aportan a la construcción de un concepto y a su caracterización, a fin de concretar sus postulados y tesis, para cotejarlos con la figura de la responsabilidad social empresarial - RSE en el área medioambiental, logrando de esta forma concretar una propuesta de obligatoriedad de dichas prácticas.

En el texto Constitucionalismo principialista y constitucionalismo garantista el autor Luigi Ferrajoli (2011, pp. 15-53) presenta un contexto de cada tipo de constitucionalismo, el principialista (más cercano al iusnaturalismo) y el garantista (vinculado al iuspositivismo). Los efectos y elementos que tiene el constitucionalismo en determinado Estado se analizan por el autor determinando, por ejemplo, la presencia de un catálogo de límites formales y materiales a través de la consolidación de los derechos fundamentales en una Constitución, o la necesidad de coherencia (en el marco de la teoría del derecho) entre las normas y los principios de justicia constitucional. Este último aspecto resulta trascendental en la medida en que Ferrajoli esboza un gran cambio en el concepto de norma válida; es decir, se pasa de un modelo legalista donde el cumplimiento de la norma procedimental validaba una norma, hacia un modelo donde el contenido de esta es lo revisado, puesto que no es automáticamente válida la norma producida con atención a los procedimientos establecidos, su validez se da por el estudio de su contenido y su coherencia con el sistema. Su descripción del constitucionalismo se basa en los siguientes elementos: a) Separación entre principios y reglas: la diferencia entre estos estriba en que los principios se cumplen en mayor o menor grado y debe ponderarse de acuerdo con el grado de afectación, mientras que las reglas se observan o se inobservan, sin puntos medios o graduales. b) Papel central de la argumentación: este rol se da con ocasión a la presencia de valores dentro de los ordenamientos jurídicos que deben incorporarse en la solución de casos difíciles. c) Derecho como práctica social confiada a los jueces: a esta tesis se suscribe Manuel Atienza, pues considera que el derecho va más 
allá de las normas. d) El derecho se enfoca como hecho, no como norma: se resume en ser y deber ser.

Por otra parte, el autor Manuel Atienza (2011, pp. 73-88) plantea que el constitucionalismo cuenta con las siguientes características:

1. Los derechos tienen una dimensión normativa de principios y de reglas y una dimensión axiológica o valorativa.

2. No siempre se requiere de una ponderación para aplicar un derecho.

3. Ve el Derecho no solo como un conjunto de normas sino también como una práctica social, que no puede reducirse al papel judicial (aunque sí tenga una relevancia evidente).

4. No reduce el Derecho a la dimensión argumentativa, solo resalta su papel teórico-práctico, pues vuelve operativas muchas teorías elaboradas por autores iuspositivistas.

Una vez caracterizado el constitucionalismo, resulta evidente que la corriente principialista sustenta la obligatoriedad de las prácticas socialmente responsables, puesto que defiende la idea de supremacía constitucional, plantea a la Constitución como norma fundante conformada, tanto por reglas como por principios. Frente a los principios se resalta su complejidad dentro del ordenamiento jurídico, pero también su exigibilidad, que unida a la teoría de Humberto Ávila, ya mencionada, plantea la necesidad de señalar el camino que deben seguir los principios constitucionales para trascender del texto a la acción.

El papel de los jueces resulta trascendental al momento de justificar la obligatoriedad en el cumplimiento de la prácticas socialmente responsables en materia medioambiental por parte de las empresas en Colombia, pues si se concibe al operador judicial, en la versión antigua referida al mero aplicador de la ley sin interpretación ni argumentación, se estaría cercenando el gran avance en materia de derechos humanos y sus garantías, por el contrario, si el papel del juez y su perfil se observa a través del constitucionalismo principialista, en sus decisiones se podrá encontrar interpretación de las normas, aplicación preferente de la Constitución y sus principios, pero más que nada, se podrá evidenciar la finalidad de mejorar la calidad de vida y promover un desarrollo sustentable.

\section{CONCLUSIONES}

La Responsabilidad Social Empresarial en el área medioambiental supone un reto para Estados, particulares y empresas, para el Estado colombiano se configura una obligación de exigencia a la empresa del cumplimiento de prácticas que resulten, no solo reparadoras de un eventual daño ambiental, sino preventivas, que guíen el actuar empresarial hacia la preservación y protección medioambiental, principalmente porque los instrumentos internacionales ratificados por Colombia le imprimen el compromiso de garantizar los derechos humanos a la salud y al medioambiente sano. Representa un reto para los particulares, en la medida en que conocen sus derechos 
humanos, las garantías de los mismos y los fundamentos legales y constitucionales que las sostienen, pero hasta el momento no identifican los mecanismos para exigir acciones preventivas que eviten poner en peligro derechos como el medioambiente sano o la propia salud, de esta manera con la herramienta de la RSE en materia ambiental, se aproximan en mayor medida a la efectividad de sus derechos.

Para la empresa la obligación de cumplir con la RSE en materia medioambiental, se configura a partir del ordenamiento jurídico nacional y de los instrumentos internacionales, vistos a través del constitucionalismo principialista, que indica, sin lugar a dudas, que al ser Colombia un Estado social de derecho, cuya norma fundante es la Constitución, compuesta por reglas y principios, exige a la empresa, al explotar la actividad económica en el territorio nacional, cumplir con las disposiciones que jurídicamente emanan, como es el caso de los principios de función social y ecológica de la propiedad y de la empresa. Dichos principios indican nada menos que un límite a la libertad de la iniciativa privada. El límite se basa en la preocupación por el entorno en el cual se desarrolla una empresa, especialmente en materia ambiental, pues esta comporta una garantía de supervivencia del ser humano e invita a unir esfuerzos con los demás entes del Estado y del mundo, para preservar lo referente a recursos naturales y derechos que de allí derivan. El actuar empresarial se ve obligado a desplegar acciones concretas en materia de preservación ambiental, a fin de prevenir cualquier posibilidad de daño al medioambiente y garantizar los derechos de los individuos que se convierten en stakeholders de la empresa. El análisis de las disposiciones normativas, jurisprudencias y tesis doctrinales, confirman el carácter de obligatoriedad de la RSE en materia medioambiental, por elementos como el factor de riesgos mayúsculo que tiene la empresa frente al particular de producir afectaciones al entorno en el cual se desarrolla, además de ampliar la visión de la empresa de generador de ganancias exclusivamente hacia una visión que incluya preocupación por el bienestar social y por el desarrollo sustentable.

\section{REFERENCIAS}

Atienza, M. (2011). Dos versiones del constitucionalismo. Doxa, Cuadernos de Filosofía del Derecho, 34, 73-88.

Ávila, H. (2011). Teoría de los principios, pp. 70-71. (10 a ed., trad. Laura Criado Sánchez). Madrid, Barcelona, Buenos Aires: Marcial Pons.

Calderón, J. (2018). La puerta de la justiciabilidad de los derechos económicos, sociales, culturales y ambientales en el Sistema Interamericano: relevancia de la sentencia Lagos del Campo. En Ferrer, E., Morales, M. y Flores, R. (Coords.). Inclusión, ius commune y justiciabilidad de los DESCA en la jurisprudencia interamericana el caso Lagos del Campo y los nuevos desafíos (1 $1^{\mathrm{a}}$ ed., p. 370). Instituto de Estudios Constitucionales del Estado de Querétaro. México.

Cancino, C., y Morales, M. (2008). Responsabilidad Social Empresarial (pp. 13 -14). Departamento Control de Gestión y Sistemas de Información de la Facultad de 
Economía y Negocios, Universidad de Chile [en línea]. Recuperado en noviembre de 2017, de http://repositorio.uchile.cl/bitstream/handle/2250/122747/Cancino_ Morales_2008.pdf?sequen

Comisión de las Comunidades Europeas. (2001). Libro Verde. [en línea]. Recuperado en enero de 2018, de http://www.europarl.europa.eu/meetdocs/committees/ deve/20020122/com(2001)366_es.pdf

Congreso de Colombia. (2010). Ley 1382 modificatoria del Código de Minas. Diario Oficial, número 47.618, artículo 27. [en línea]. Recuperado en febrero de 2018, de https://www.funcionpublica.gov.co/eva/gestornormativo/norma.php?i=38863

Congreso de la República. (1991, julio 6). Constitución Política de Colombia. Bogotá [en línea]. Recuperado en noviembre de 2017, de http://www.secretariasenado. gov.co/senado/basedoc/constitucion_politica_1991.html

Davis, M. (2018). La deforestación en el mundo. Uruguay: Iberciencia [en línea]. Recuperado en marzo de 2018, de http://www.oei.es/historico/ divulgacioncientifica/?La-deforestacion-en-el-mundo

Departamento de Asuntos Económicos y Sociales de Naciones Unidas ONU-DAES. (2014). Decenio internacional para la acción "el agua fuente de vida" 20052015 [en línea]. Recuperado en mayo de 2018, de http://www.un.org/spanish/ waterforlifedecade/quality.shtml

Earth Observatory (Observatorio de la tierra) (s.f.). ¿Cuánto más se calentará la tierra? Estados Unidos de América, NASA [en línea]. Recuperado en mayo de 2018, de https://earthobservatory.nasa.gov/Features/GlobalWarming/page5.php

Environmental Protection Agencies (Agencias de Protección Ambiental). (2018). Contaminación del aire del mundo - mapa de la calidad del aire en tiempo real. [en línea]. Recuperado en abril de 2018, de http://aqicn.org/map/world/ es/\#@g/23.0789/8.2617/2z

Ferrajoli, L. (2011). Constitucionalismo principialista y constitucionalismo garantista. (Trad. Nicolás Guzmán). Revista Doxa, Cuadernos de Filosofía del Derecho, Núm. 34, 15-53. Madrid.

Freeman, E. (2010). Gestión estratégica, pp. 31-32. Nueva York: Cambridge University Press. Versión digital [en línea]. Recuperado en agosto de 2017, de https://books.google.com

Gallardo, M.A. (2010). Estudios y evidencias del calentamiento global. Chile [en línea]. Recuperado en mayo de 2018, de https://cambioclimaticoglobal.com/ estudios-y-evidencias-del-calentamiento-global

Góngora, J. J. (2018). Pasado, presente - ¿y futuro?- de los derechos económicos, sociales, culturales y ambientales, en la jurisprudencia de la Corte Interamericana: a propósito del caso: Lagos del Campo vs. Perú. En Ferrer, E., Morales, M. y Flores, R. (Coords.). Inclusión, ius commune y justiciabilidad de los DESCA en la jurisprudencia interamericana el caso Lagos del Campo y los nuevos 
desafíos. ( $1^{\text {a }}$ ed., pp. 283). México: Instituto de Estudios Constitucionales del Estado de Querétaro.

Instituto Argentino de Responsabilidad Social Empresarial - IARSE. (s.a.). Algunas definiciones de responsabilidad social empresarial. Kellogg Fundación y Fundación AVINA. Argentina, [en línea]. Recuperado en septiembre de 2017 de http://www.iarse.org/uploads/59069_Algunas\%20Definiciones\%20de $\% 20$ RSE\%20(1).pdf López de Medina, L. (2002). La empresa, el medio ambiente y la responsabilidad social. Revista Galega de Economía, 11(2), 1-5 [en línea]. Recuperado en enero de 2018, de http://www.usc.es/econo/RGE/Vol\%2011_2/ Castelan/op4.pdf

Ministerio del Medioambiente. (1995). Decreto 948 del 5 de junio de 1995. [en línea]. Recuperado en febrero de 2018, de http://www.encolombia.com/medioambiente/ hume-decreto094895.htm

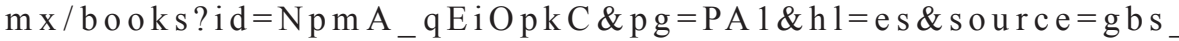
toc $\mathrm{r} \& \mathrm{cad}=4 \# \mathrm{v}=$ onepage $\& \mathrm{q}=$ history $\% 20 \mathrm{of} \% 20$ stakeholder $\& \mathrm{f}=$ false

Naciones Unidas, Asamblea General. (2014). Resolución AG/RES. 2840 (XLIV-O/14), sobre la promoción y protección de los derechos humanos en el ámbito empresarial. [en línea] Recuperado en marzo de 2018, de https://www.oas.org/ es/sla/ddi/docs/AG-RES_2840_XLIV-O-14.pdf

Naciones Unidas. (1992). Conferencia sobre medioambiente y el desarrollo. Río de Janeiro. [en línea]. Recuperado en octubre de 2017, de http:/www.un.org/ spanish/conferences/wssd/unced.html

Naciones Unidas. (1998). Protocolo de Kioto. Japón. [en línea] Recuperado en octubre de 2017, de https://unfccc.int/resource/docs/convkp/kpspan.pdf

Naciones Unidas. (2011). Principios rectores sobre las empresas y los derechos humanos. Nueva York y Ginebra. [en línea] Recuperado en marzo de 2018, de http://www.ohchr.org/documents/publi

Naciones Unidas. (2011). Principios rectores sobre las empresas y los derechos humanos. Nueva York y Ginebra [en linea]. Recuperado en marzo de 2018, de http://www.ohchr.org/documents/publications/guidingprinciples businesshr sp.pdf

Naciones Unidas. (2015). Acuerdo de París. Francia. [en línea] Recuperado en octubre de 2017, de https://unfccc.int/files/meetings/paris_nov_2015/application/pdf/ paris_agreement_spanish_.pdf

Naciones Unidas. (s.f.). ¿Qué es la biodiversidad? [en línea]. Recuperado en mayo de 2018, de http://www.un.org/es/events/biodiversityday/background.shtml

Nowajewski, F. et al. (s.f.). Responsabilidad Social Empresarial (RSE): Evolución, Presentey Tendencias, pp. 3-5. Universidad de Chile. Chile. [en línea] Recuperado en agosto de 2017, de https:/www.dii.uchile.cl/wp-content/uploads/2015/11/ Ensayo-RSE.pdf RESPONSABILIDAD_SOCIAL_EMPRESARIAL 
Reyno, M. (2006), Responsabilidad Social Empresarial (RSE) como ventaja competitiva, pp. 34-35. Universidad Técnica Federico Santa María. Chile. [en línea] Recuperado en octubre de 2017, de http://www.eumed.net/librosgratis/2008c/436/index.htm

Sentencia C-486 (M.P. María Victoria Calle Correa). Gaceta de la Corte Constitucional 2009. [en línea] Recuperado en febrero de 2018, de http://www. corteconstitucional.gov.co/RELATORIA/2009/C-486-09.htm

Sentencia C-944 (M.P. Nilson Pinilla Pinilla). Gaceta de la Corte Constitucional 2008. [en línea] Recuperado en enero de 2018, de http://www.corteconstitucional. gov.co/relatoria/2008/C-944-08.htm

Universidad de San Martin de Porres. Universidad Interna. (2013). La Universidad Interna 2013. Gestión ambiental y responsabilidad social, pp. 17-22. Perú. [en línea] Recuperado en febrero de 2018, de https://ocplayer.es/13594409-Launiversidad-interna-2013-gestion-ambiental-y-responsabilidad-social.html

Universidad Interna. (2013). Gestión ambiental y responsabilidad social. Universidad de San Martin de Porres. Perú. [en línea]. Recuperado en febrero de 2018, de http://www.usmp.edu.pe/recursoshumanos/pdf/sesion1-gestionambiental.pdf

Vigo, R. L. (2015). Estado constitucional, derechos humanos, justicia y vida universitaria. Estudios en homenaje a Jorge Carpizo. (T. IV, Vol. 2). México, Universidad Nacional Autónoma de México, Instituto de Investigaciones Jurídicas. [en línea]. Recuperado en noviembre de 2017 de https://archivos. juridicas.unam.mx/www/bjv/libros/8/3845/35.pdf 